\title{
Effects of 9,300 nm Carbon Dioxide Laser on Dental Hard Tissue: A Concise Review
}

\author{
Vicky Wenqing Xue (ID ${ }^{1,2}$ \\ Irene Shuping Zhao ${ }^{1}{ }^{\prime}$ \\ Iris Xiaoxue Yin (iD ${ }^{2}$ \\ John Yun Niu (iD ${ }^{2}$ \\ Edward Chin Man Lo (iD ${ }^{2}$ \\ Chun Hung Chu (iD ${ }^{2}$ \\ 'School of Dentistry, Shenzhen \\ University Health Science Center, \\ Shenzhen, People's Republic of China; \\ ${ }^{2}$ Faculty of Dentistry, The University of \\ Hong Kong, Hong Kong
}

\begin{abstract}
A carbon dioxide laser at $9,300 \mathrm{~nm}$ has a high absorption affinity for water and a shallow depth of penetration. It can be used for soft tissue surgery and hemostasis. Besides, it matches well with the absorption characteristic of hydroxyapatite in enamel and dentine. Therefore, the laser possesses a great ability for energy transfer to dental hard tissues. It has a low risk of thermo-damage to the dentine-pulp complex because it has a shallow depth of heat absorption. Hence, the laser is safe for dental hard tissue preparation. A carbon dioxide laser at 9,300 $\mathrm{nm}$ can effectively alter the chemical structure of teeth. It increases the ratio of calcium to phosphorus and converts the carbonated hydroxyapatite to the purer hydroxyapatite of enamel and dentine. It can alter the surface morphology of a tooth through surface melting, fusion, and ablation of dentine and enamel. At higher power, it removes caries lesions. It can enhance the success of restoration by increasing the bond strength of dental adhesives to the dentine and enamel. A carbon dioxide laser at 9,300 $\mathrm{nm}$ can also be used with fluoride for caries prevention. The advancement of technology allows the laser to be delivered in very short pulse durations and high repetition rates (frequency). Consequently, the laser can now be used with high peak power. The objective of this review is to discuss the effects and potential use of a 9,300 $\mathrm{nm}$ carbon dioxide laser on dental hard tissue.
\end{abstract}

Keywords: caries, prevention, fluoride, dentin, enamel, laser, carbon dioxide

\section{Introduction}

Enamel and dentine are complex hydrated biological composites. They are composed of inorganic material, organic material, and water. The major component is hydroxyapatite, which constitutes $96 \mathrm{wt} \%$ of enamel and $70 \mathrm{wt} \%$ of dentine. ${ }^{1}$ The hydroxyapatite in enamel and dentine contains a certain amount of carbonates. This substituted carbonated apatite is more soluble in acid than hydroxyapatite. ${ }^{2}$

Plenty of studies investigated the application of lasers on enamel and dentine. ${ }^{3}$ These studies used lasers at different wavelengths such as Excimer (193 nm and $308 \mathrm{~nm}$ ), semiconductor lasers (Diode laser $445 \mathrm{~nm}, 660 \mathrm{~nm}, 810 \mathrm{~nm}, 940 \mathrm{~nm}$, and $970 \mathrm{~nm}$ ), Neodymium: YAG (Nd: YAG 1,064 nm), Erbium: Yttrium Aluminum Garnet (Er:YAG, 2,940 nm), Erbium chromium: Yttrium Scandium Gallium Garnet (Er: YSGG, 2,790 nm), and carbon dioxide (9,000-11,000 nm) lasers. The absorption, reflection, and scattering on enamel and dentine vary substantially according to the wavelength of the laser used. ${ }^{4}$

Carbon dioxide lasers were the first type of laser used for dentistry. They can be operated at wavelengths between 9,000 $\mathrm{nm}$ and 11,000 $\mathrm{nm}$. A carbon dioxide laser at $10,600 \mathrm{~nm}$ is the most common laser used for dental treatment. It allows a bloodless surgical procedure and reduces post-operative discomfort in dental
Correspondence: Irene Shuping Zhao School of Dentistry, Shenzhen University Health Science Center, Shenzhen, People's Republic of China Email zhaol 10@szu.edu.cn

Chun Hung Chu

Faculty of Dentistry, The University of Hong Kong, 3B36 Prince Philip Dental Hospital, 34 Hospital Road, Hong Kong Email chchu@hku.hk 
soft tissue surgery. ${ }^{5}$ However, a $10,600 \mathrm{~nm}$ carbon dioxide laser has significantly lower absorption coefficients to hydroxyapatite than $9,300 \mathrm{~nm}$ or $9,600 \mathrm{~nm}$ wavelength. ${ }^{6,7}$ A 9,300 $\mathrm{nm}$ or 9,600 $\mathrm{nm}$ carbon dioxide laser is a desirable tool for application in dental hard tissues. The absorption of hydroxyapatite is at $9,600 \mathrm{~nm}$, whereas its reflection also peaks at $9,600 \mathrm{~nm}$. Hence, the $9,300 \mathrm{~nm}$ carbon dioxide laser possesses the greatest energy-transfer capacity on hydroxyapatite among the available dental lasers. ${ }^{5}$ The $9,300 \mathrm{~nm}$ carbon dioxide laser requires less energy to achieve the same absorption effect as other wavelengths. Therefore, it causes much less heat deposit.

Studies showed a 9,300 $\mathrm{nm}$ carbon dioxide laser can induce chemical and morphological changes of hard dental tissues. $^{6,8}$ They also found the laser effectively ablated enamel and dentine. Because it can prevent enamel caries and remove caries lesions, the $9,300 \mathrm{~nm}$ carbon dioxide laser is getting more attention in dentistry for caries management. ${ }^{9}$ The aim of this paper is to discuss the effects and potential use of 9,300 $\mathrm{nm}$ carbon dioxide lasers on dental hard tissue.

\section{Modification of Tooth Structure}

A carbon dioxide laser can modify the tooth structure and the interaction between the laser and enamel and dentine is complex. The changes of tooth structure are determined by the parameters of the laser. Apart from the wavelength, parameters such as output power, energy density, pulse duration, and repetition rate of the laser should be taken into consideration to achieve the desired effect on dental hard tissue. Table 1 summarizes the effects of the 9,300 $\mathrm{nm}$ carbon dioxide laser on tooth structure.

When enamel is irradiated with a 9,300 $\mathrm{nm}$ carbon dioxide laser, decomposition of its chemical elements happens. Also, melting and fusion of enamel may occur because the momentary temperature exceeds the threshold. The laser alters the microstructure and surface morphology of enamel after cooling. Moreover, the laser induces chemical changes in dental hard tissues such as reducing the carbonate content of dental hard tissues. The conversion of carbonated apatite crystals to purer apatite crystals makes enamel less soluble to acid challenge. ${ }^{6,10}$ Furthermore, the calcium and phosphorus content of enamel and dentine increased after the laser irradiation. ${ }^{8}$ The irradiated dentine shows three prominent intrinsic phosphate bands under Fourier transform infrared microscopy. The results indicate an increased crystallinity of dentine after the laser irradiation. ${ }^{6}$ A study found that $9,300 \mathrm{~nm}$ carbon dioxide laser irradiation increased the calcium and phosphorus ratio of sound but not carious enamel and dentine. ${ }^{8}$

Table I Studies of Effects on Enamel and Dentine by a 9,300 nm Carbon Dioxide Laser

\begin{tabular}{|c|c|}
\hline Authors, Year [Reference] & Irradiation Effects \\
\hline \multicolumn{2}{|l|}{ Enamel } \\
\hline \multirow[t]{2}{*}{ Featherstone et al, $1997^{10}$} & Alter chemical composition of enamel crystals \\
\hline & Decompose carbonate of hydroxyapatite \\
\hline \multirow[t]{3}{*}{ Takahashi et al, $1998^{8}$} & Produce crater-like structures \\
\hline & Increase the calcium and phosphorus content \\
\hline & Increase calcium-to-phosphorus ratio on enamel \\
\hline \multicolumn{2}{|l|}{ Dentine } \\
\hline \multirow[t]{3}{*}{ Takahashi et al, $1998^{8}$} & Cover dentinal tubules with material fused by laser \\
\hline & Increase the calcium and phosphorus content \\
\hline & Increase the calcium-to-phosphorus ratio on dentine \\
\hline \multirow[t]{2}{*}{ Kimura et al, $2000^{42}$} & Produce small cracks in the subsurface layer \\
\hline & Produce surface with molten and solidified particles \\
\hline \multirow[t]{2}{*}{ Fried et al, $2002^{6}$} & Cause fusion of the individual dentine crystallites \\
\hline & Eliminate carbonate, water, and protein amide \\
\hline
\end{tabular}


Basically, the higher the calcium to phosphorus molar ratio is, the lower solubility the calcium phosphate compound has. The results also suggest that the laser irradiation evaporated the organic components in carious enamel and dentine.

Laser irradiation at appropriate parameters can produce a melting surface of dentine. A homogenous and smooth dentine surface can be formed. ${ }^{11}$ The irradiation was able to induce fusion of individual crystallites to generate a hypercrystalline-like matrix. ${ }^{6}$ However, laser irradiation at high energy results in carbonization. It also causes loss of the collagen matrix and tissue contraction. As a result, cracks can occur on the dentine surface. These cracks weakened resistance of dentine to demineralization under acid challenge. ${ }^{6}$ A study found after laser irradiation at high energy, the tubules at the dentine surface remained patent, although they were partially fused by the laser. ${ }^{6}$ More research is needed to determine the effect of a 9,300 $\mathrm{nm}$ carbon dioxide laser on enamel and dentine.

\section{Insignificant Thermal Effect on Pulp}

The temperature rise in the pulp chamber should not exceed $5.5^{\circ} \mathrm{C}$ for laser treatment. Otherwise, excessive heat accumulation would cause thermal trauma to the dentine-pulp complex, such as destruction and disruption of odontoblasts or even pulp necrosis. ${ }^{12}$ A series of studies reported that the thermal effect of $9,300 \mathrm{~nm}$ carbon dioxide laser irradiation on pulp was shown to be minimal ${ }^{13,14}$ because the laser will be absorbed very near to the surface of the hard tissues and rapidly transformed to heat. ${ }^{15}$ Compared with $9,300 \mathrm{~nm}$ or 9,600 $\mathrm{nm}$ carbon dioxide lasers, a 10,600 $\mathrm{nm}$ carbon dioxide laser requires more incident energy for a similar inhibition effect. ${ }^{5}$ In addition, the pulp chamber temperature can increase $10^{\circ} \mathrm{C}$ at similar incident energy, which is detrimental to the dentine-pulp complex. $^{16}$

Studies demonstrated that air or water aerosol spray could efficiently reduce the heat accumulation by laser. $^{13,17}$ They also showed that the bond strength to dentine was reduced with no water cooling during laser irradiation. Depending on the power selected, the heat generated by laser could affect and even damage the structural integrity of dentine. In contrast, the temperature rise was always below $5.5^{\circ} \mathrm{C}$ for all samples with water spray, and the surfaces were highly smooth and homogenous. A clinical study reported even operating at relatively high energy and without water cooling, a 9,300 nm carbon dioxide laser could ablate enamel with no pulpal damage.
Table 2 Studies on Effect of 9,300 nm Carbon Dioxide Laser on Pulp

\begin{tabular}{|l|l|}
\hline $\begin{array}{l}\text { Authors, Year } \\
\text { [Reference] }\end{array}$ & Irradiation Effects \\
\hline Assa et al, $2008^{13}$ & Temperature rise below $5.5^{\circ} \mathrm{C}$ with water \\
\hline Staninec et al, 200917 & $\begin{array}{l}\text { Temperature rise below } 5.5^{\circ} \mathrm{C} \text { with or } \\
\text { without water }\end{array}$ \\
\hline Nguyen et al, 201 ${ }^{14}$ & $\begin{array}{l}\text { Temperature rise below } 5.5^{\circ} \mathrm{C} \text { with or } \\
\text { without water } \\
\text { Normal vascular pattern with no } \\
\text { enlargement or engorgement } \\
\text { No inflammatory response or cell infiltrate }\end{array}$ \\
\hline
\end{tabular}

However, the tooth surface irradiated with no water cooling was uneven with white asperities. This change could adversely affect its adhesion to resin and its resistance to acid challenge. ${ }^{17}$ Table 2 summarizes the studies of the effect of 9,300 nm carbon dioxide laser on the pulp.

\section{Prevention of Enamel Caries}

When a tooth is irradiated with a $9,300 \mathrm{~nm}$ carbon dioxide laser, its energy is mostly absorbed by apatite and converted into heat energy at the surface or subsurface zone. The chemical composition of enamel will change when the temperature reaches $400^{\circ} \mathrm{C}$. Melting of enamel will happen when the temperature is above $800^{\circ} \mathrm{C}$. Ablation of enamel will occur when the temperature is above $1200^{\circ} \mathrm{C}$.

Studies demonstrated that irradiation by a $9,300 \mathrm{~nm}$ carbon dioxide laser at sub-ablative energy could effectively prevent enamel caries. ${ }^{9,16,18,19}$ They showed that enamel with sub-ablative irradiation reduced up to $70 \%$ caries development. Furthermore, the irradiated enamel demonstrated surface melting was more resistant to acid attack than those with no melting at all.

Most dentists use burs as the traditional or mechanical approach for caries removal. The 9,300 $\mathrm{nm}$ carbon dioxide laser offers an alternative approach for caries removal. Studies reported that a $9,300 \mathrm{~nm}$ carbon dioxide laser guided by near-infrared reflectance image could selectively remove caries lesions on occlusal and smooth surfaces. $^{20-25}$ Studies also revealed that the ablated surfaces of enamel or dentine were more acidresistant. ${ }^{26,27}$ The studies demonstrated the use of 9,300 $\mathrm{nm}$ carbon dioxide as a conservative technique of caries and cavity preparation. A study found the enamel ablated by carbon dioxide laser had a significantly lower calcium and phosphate loss after acid challenge than the control 
group. ${ }^{27}$ Another study investigated the inhibition of secondary caries by laser ablation and observed that a 9,300 $\mathrm{nm}$ carbon dioxide laser could produce a cavity surface morphology with marked resistance to artificial secondary caries compared to mechanical removal. ${ }^{26}$ Therefore, using a 9,300 $\mathrm{nm}$ carbon dioxide laser in cavity preparation for restoration has a promising future in preventing secondary caries.

Carbon dioxide laser irradiation causes chemical modification to dental hard tissues. Studies found the irradiated enamel and dentine had complete loss of the two carbonate bands, a narrowing of the phosphate peak, and an increase of calcium to phosphorous molar ratio. ${ }^{27,28}$ This suggested the soluble carbonate impurities were removed from the hydroxyapatite, which become less soluble. Carbon dioxide laser irradiation also causes morphological changes of enamel and dentine which demonstrated resistance to acid challenge. The morphological or chemical modification to dental hard tissues are related to the caries-preventive effect of a carbon dioxide laser.

These findings reasonably explain the mechanisms of caries prevention by carbon dioxide laser. The inhibition of demineralization can most likely be attributed to thermal decomposition of the more soluble carbonated hydroxyapatite and transformation into purer phase hydroxyapatite, with corresponding changes of crystal structure. It has been postulated that modification of the protein matrix and permeability changes by laser irradiation or ablation strengthen the resistance of enamel and dentine to acid attack and play a role in caries prevention. ${ }^{28}$ Table 3 summarizes the studies of 9,300 $\mathrm{nm}$ carbon dioxide lasers on prevention of enamel caries.

Fluoride is effective in preventing enamel demineralization. Besides, fluoride in high concentration inhibits bacterial enzymes. ${ }^{29}$ A carbon dioxide laser at 9,300 nm is effective in converting carbonated hydroxyapatite to a purer phase hydroxyapatite with more resistance to acid challenge. Fluoride promotes formation of fluorapatite which is even more resistant to acid dissolution. ${ }^{30}$ A study found that laser-activated fluoride therapy reduced the critical acidity $(\mathrm{pH})$ at which enamel dissolved. ${ }^{31}$ Hence, a combination of the laser irradiation and the fluoride could produce a synergistic effect on caries prevention. ${ }^{31}$ The study also showed that the action spectrum of the laser-activated fluoride effect was across the visible and near-infrared wavelengths, including the wavelengths of carbon dioxide laser.

A clinical trial reported that combined 9,600 nm carbon dioxide laser irradiation with fluoride varnish
Table 3 Studies of Prevention of Enamel Caries by 9,300 nm Carbon Dioxide Laser

\begin{tabular}{|l|l|}
\hline $\begin{array}{l}\text { Authors, Year, } \\
\text { [Reference] }\end{array}$ & Caries Preventive Effects \\
\hline $\begin{array}{l}\text { Featherstone et al, } \\
\left.199\right|^{43}\end{array}$ & Arrest progression of caries \\
\hline $\begin{array}{l}\text { Featherstone et al, } \\
1998^{16}\end{array}$ & Inhibit caries development \\
\hline Konishi et al, $1999^{26}$ & $\begin{array}{l}\text { Prevent secondary caries of composite } \\
\text { restoration }\end{array}$ \\
\hline Fried et al, 2006 & Enhance resistance to acid dissolution \\
\hline Rechmann et al, 2016 & $\begin{array}{l}\text { Inhibit acid dissolution and reduce } \\
\text { mineral loss }\end{array}$ \\
\hline
\end{tabular}

application promoted remineralization and inhibited development of fissure caries in molars. ${ }^{32}$ Accordingly, a 9,300 $\mathrm{nm}$ laser may perform similarly because their absorption characteristics of dental hard tissues are similar. Nevertheless, only a few studies on 9,300 nm carbon dioxide lasers and no clinical trial can be found in the literature. Most of the studies examined enamel caries. They used acidulated phosphate fluoride, sodium fluoride,

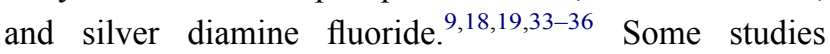
showed that enamel treated with a $9,300 \mathrm{~nm}$ carbon dioxide laser before fluoride treatment had less mineral loss after acid challenge than those treated with laser or fluoride. ${ }^{9,18,33,35}$ Also, 9,300 $\mathrm{nm}$ carbon dioxide laser irradiation before fluoride can also enhance the cariespreventive effect of fluoride on enamel and dentine. ${ }^{19,34,36}$ There is only one paper studying the combined treatment of a 9,300 $\mathrm{nm}$ carbon dioxide laser and fluoride on dentine. The study demonstrated that, compared with a laser group, the combined treatment group showed an increase in resistance of dentine to demineralization. However, the combined treatment did not show any difference in resistance to demineralization compared with topical fluoride treatment. ${ }^{37}$ Current evidence of the effectiveness of the treatment combining 9,300 nm carbon dioxide laser and fluoride on preventing dentine caries is insufficient and more research is needed to draw a conclusion.

\section{Enhancing Resin Bonding to Enamel}

The effect of carbon dioxide laser on bond strength of resin to enamel and dentine is irradiation-energy- 
dependent. Sub-ablative irradiation on an enamel surface before etch-and-rinse could increase the shear bond strength of composite resin to enamel. ${ }^{38}$ However, compared to etch-and-rinse, ablative irradiation before etching cannot enhance shear bond strength of enamel to resin. $^{38-40}$ The high irradiation energy causes thermal damage to enamel. Large white asperities can be formed on the enamel surface when ablated with high energy. The asperities are loosely attached to the surface and they compromise adhesion to restorative materials. ${ }^{27}$

Ablative irradiation or sub-ablative before using selfetch system could increase the shear bond strength of resin to enamel. ${ }^{39}$ Nevertheless, ablative irradiation or subablative on dentine before using a self-etch system could not increase the shear bond strength of resin to dentine. ${ }^{39}$ In this review, studies showed that additional etching after laser irradiation on dental hard tissues is necessary. Table 4 summarizes studies of resin bond strength to enamel and dentine with irradiation of a 9,300 nm carbon dioxide laser.

\section{Clinical Use of $9,300 \mathrm{~nm}$ Carbon Dioxide Laser}

At present, a 10,600 nm carbon dioxide laser is the most common carbon dioxide laser device on the market. However, its excessive heat accumulation and less efficiency in operation limits its application in clinical treatment. A carbon dioxide laser at 9,300 $\mathrm{nm}$ matches well the absorption characteristics of dental hard tissues. Therefore,

Table 4 Studies of Resin Bond Strength to Enamel and Dentine with Irradiation of $9,300 \mathrm{~nm}$ Carbon Dioxide Laser

\begin{tabular}{|c|c|}
\hline Authors, Year [Reference] & Resin Bond Strength \\
\hline Enamel & \\
\hline Nguyen et al, 201 $1^{40}$ & $\mathrm{aL}+\mathrm{ER}=\mathrm{ER}>\mathrm{aL}$ \\
\hline Rechmann et al, $2017^{38}$ & $\begin{array}{l}s L+E R>E R>s L \\
a L+E R>E R>a L\end{array}$ \\
\hline Rechmann et al, $2017^{39}$ & $\begin{array}{l}s L+E R>E R \\
a L+E R<E R\end{array}$ \\
\hline Dentine & \\
\hline Nguyen et al, 201 I ${ }^{40}$ & $\mathrm{aL}<\mathrm{aL}+\mathrm{ER}<\mathrm{ER}$ \\
\hline Rechmann et al, $2017^{39}$ & $\begin{array}{l}s L+E R<E R \\
a L+E R<E R\end{array}$ \\
\hline
\end{tabular}

Abbreviations: $s L$, sub-ablative irradiation; aL, ablative irradiation; ER, etch and rinse. it can localize heat deposition to the surface and reduce the risks of thermal damage to the pulp. A study reported that both dentists and patients were satisfied with 9,300 nm carbon dioxide laser treatment. More importantly, the laser could be used safely, effectively, quickly, and comfortably for caries removal and cavity preparation. ${ }^{15}$ Current evidence suggests that a 9,300 $\mathrm{nm}$ carbon dioxide laser can successfully inhibit enamel demineralization. Moreover, laser irradiation enhances the bond strength of resin to enamel. Most of the studies support that the combined use of laser irradiation and topical fluoride has a synergistic effect on caries prevention.

A study found that a $10,600 \mathrm{~nm}$ carbon dioxide laser inhibited biofilm growth and reduced bacteria viability. ${ }^{4}$ No study was found using a 9,300 $\mathrm{nm}$ carbon dioxide laser, which is worth investigating in future studies. In addition, few studies are related to its effect on preventing or arresting dentine caries (root caries). It is still not known whether a 9,300 $\mathrm{nm}$ carbon dioxide laser can effectively remineralize dental caries as a $10,600 \mathrm{~nm}$ carbon dioxide laser does, ${ }^{41}$ so further related studies are warranted. The 9,300 $\mathrm{nm}$ carbon dioxide laser is a promising treatment for caries control. Because there are a limited number of studies in the literature, further research is essential to develop a clinical protocol for the laser's use in dentistry. Currently, there is one commercially available 9,300 $\mathrm{nm}$ carbon dioxide laser (Solea, Convergent Dental, Inc., Needham, MA, USA) cleared by the US Food and Drug Administration. This computercontrolled 9,300 $\mathrm{nm}$ carbon dioxide laser generates a galvanometer-guided laser beam. The foot pedal allows speed control to provide laser irradiation with precision and control. It allows adjustment of irradiation parameters including the pulse energies, repetition rates, and spot diameters for fine cutting of enamel. The pulse duration is specifically designed to match the thermal relaxation time of enamel and dentine to prevent damage to the dental pulp. The safety of its use can be further enhanced with the use of water to cool the lased dental hard tissue.

\section{Conclusions}

A carbon dioxide laser at 9,300 $\mathrm{nm}$ matches the absorption characteristics of hydroxyapatite. The laser energy can be effectively transferred to enamel and dentine. It converts the carbonated hydroxyapatite to the purer hydroxyapatite of enamel and dentine. Because 9,300 nm laser carbon dioxide has a shallow depth of heat absorption in enamel and dentine, it reduces the risk of thermo-damage to the 
dentine-pulp complex. The laser fosters the effect of fluoride on caries prevention. It enhances bonding of resin to enamel. It can also be used at high power to ablate caries for restorative treatment.

\section{Disclosure}

The authors declare no conflicts of interest for this work.

\section{References}

1. Zhang Y, Wang Y. Improved degree of conversion of model self-etching adhesives through their interaction with dentine. J Dent. 2012;40(1):57-63. doi:10.1016/j.jdent.2011.10.004

2. Taube F, Ylmén R, Shchukarev A, Nietzsche S, Norén JG. Morphological and chemical characterization of tooth enamel exposed to alkaline agents. $J$ Dent. 2010;38(1):72-81. doi:10.1016/ j.jdent.2009.09.006

3. Verma SK, Maheshwari S, Singh RK, Chaudhari PK. Laser in dentistry: an innovative tool in modern dental practice. Natl J Maxillofac Surg. 2012;3:124-132. doi:10.4103/0975-5950.111342

4. Luk K, Yu OY, Mei ML, Gutknecht N, Chu CH, Zhao IS. Effects of carbon dioxide lasers on preventing caries: a literature review. Lasers Dent Sci. 2019;3(2):83-90. doi:10.1007/s41547-019-00065-8

5. Luk K, Zhao IS, Gutknecht N, Chu CH. Use of carbon dioxide lasers in dentistry. Lasers Dent Sci. 2019;3(1):1-9. doi:10.1007/s41547018-0047-y

6. Fried D, Zuerlein MJ, Le CQ, Featherstone JD. Thermal and chemical modification of dentin by $9-11-\mu \mathrm{m} \mathrm{CO} 2$ laser pulses of $5-100-\mu \mathrm{s}$ duration. Lasers Surg Med. 2002;31(4):275-282. doi:10.1002/ 1sm. 10100

7. Featherstone JD, Fried D. Fundamental interactions of laserswith dental hard tissues. Med Laser Appl. 2001;16(3):181-194. doi:10.1078/1615-1615-00022

8. Takahashi K, Kimura Y, Matsumoto K. Morphological and atomic analytical changes after $\mathrm{CO}_{2}$ laser irradiation emitted at $9.3 \mu \mathrm{m}$ on human dental hard tissues. J Clin Laser Med Surg. 1998;16 (3):167-173. doi:10.1089/clm.1998.16.167

9. Rechmann P, Rechmann BM, Groves WH Jr, et al. Caries inhibition with a $\mathrm{CO}_{2} 9.3 \mu \mathrm{m}$ laser: an in vitro study. Lasers Surg Med. 2016;48 (5):546-554. doi:10.1002/1sm.22497

10. Featherstone JD, Fried D, Bitten ER. Mechanism of laser-induced solubility reduction of dental enamel. Lasers in Dentistry III: International Society for Optics and Photonics; 1997:112-116.

11. Le CQ, Fried D, Featherstone JD. Lack of dentin acid resistance following $9.3 \mu \mathrm{m} \mathrm{CO}_{2}$ laser irradiation. Lasers in dentistry XIV: International Society for Optics and Photonics; 2008:68430J.

12. Kwon SJ, Park YJ, Jun SH, et al. Thermal irritation of teeth during dental treatment procedures. Restor Dent Endod. 2013;38:105-112. doi:10.5395/rde.2013.38.3.105

13. Assa S, Meyer S, Fried D. Ablation of dental hard tissues with a microsecond pulsed carbon dioxide laser operating at $9.3-\mu \mathrm{m}$ with an integrated scanner. Proc SPIE Int Soc Opt Eng. 2008;6843:684308. doi:10.1117/12.778799

14. Nguyen D, Chang K, Hedayatollahnajafi S, et al. High-speed scanning ablation of dental hard tissues with a $\lambda=9.3 \mu \mathrm{m} \mathrm{CO}_{2}$ laser: adhesion, mechanical strength, heat accumulation, and peripheral thermal damage. J Biomed Opt. 2011;16:071410. doi:10.1117/1.3603996

15. Fantarella D, Kotlow L. The $9.3-\mu \mathrm{m} \mathrm{CO}{ }_{2}$ dental laser: technical development and early clinical experiences. $J$ Dent Lasers. 2014;22:1.

16. Featherstone J, Barrett-Vespone N, Fried D, Kantorowitz Z, Seka W. $\mathrm{CO}_{2}$ laser inhibition of artificial caries-like lesion progression in dental enamel. J Dent Res. 1998;77:1397-1403. doi:10.1177/ 00220345980770060401
17. Staninec M, Darling CL, Goodis HE, et al. Pulpal effects of enamel ablation with a microsecond pulsed $\lambda=9.3-\mu \mathrm{m} \mathrm{CO}_{2}$ laser. Lasers Surg Med. 2009;41:256-263. doi:10.1002/lsm.20748

18. Rechmann P, Le CQ, Kinsel R, Kerbage C, Rechmann BMT. In vitro $\mathrm{CO}_{2}$ 9.3- $\mu \mathrm{m}$ short-pulsed laser caries prevention-effects of a newly developed laser irradiation pattern. Lasers Med Sci. 2020;35:979-989. doi:10.1007/s10103-019-02940-z

19. Badreddine AH, Couitt S, Donovan J, Cantor-Balan R, Kerbage C, Rechmann P. Demineralization inhibition by high-speed scanning of $9.3 \mu \mathrm{m} \mathrm{CO}$ single laser pulses over enamel. Lasers Surg Med. 2020. doi: $10.1002 / 1 \mathrm{sm} .23340$

20. Chan KH, Fried D. Selective removal of demineralization using near infrared cross polarization reflectance and a carbon dioxide laser. Lasers in Dentistry XVIII: International Society for Optics and Photonics; 2012:82080U.

21. Tom H, Chan KH, Saltiel D, Fried D. Selective removal of demineralized enamel using a $\mathrm{CO}_{2}$ laser coupled with near-IR reflectance imaging. Lasers in Dentistry XXI: International Society for Optics and Photonics; 2015:93060M.

22. Tom H, Chan KH, Darling CL, Fried D. Near-IR image-guided laser ablation of demineralization on tooth occlusal surfaces. Lasers Surg Med. 2016;48(1):52-61. doi:10.1002/lsm.22438

23. Chan KH, Fried NM, Fried D. Selective ablation of carious lesions using an integrated multispectral near-IR imaging system and a novel 9.3- $\mu \mathrm{m} \mathrm{CO}_{2}$ laser. Lasers in Dentistry XXIV: International Society for Optics and Photonics; 2018:104730E.

24. Ngo A, Chan KH, Le O, Simon JC, Fried D. Image-guided removal of interproximal lesions with a $\mathrm{CO}_{2}$ laser. Lasers in Dentistry XXIV: International Society for Optics and Photonics; 2018:104730T.

25. Chan KH, Fried D. Selective ablation of dental caries using coaxial $\mathrm{CO}_{2}(9.3-\mu \mathrm{m})$ and near-IR $(1880-\mathrm{nm})$ lasers. Lasers Surg Med. 2019;51(2):176-184. doi:10.1002/1sm.23002

26. Konishi N, Fried D, Staninec M, Featherstone J. Artificial caries removal and inhibition of artificial secondary caries by pulsed $\mathrm{CO}_{2}$ laser irradiation. Am J Dent. 1999;12(5):213-216.

27. Fried D, Featherstone JD, Le CQ, Fan K. Dissolution studies of bovine dental enamel surfaces modified by high-speed scanning ablation with a $\lambda=9.3-\mu \mathrm{m}$ TEA $\mathrm{CO}_{2}$ laser. Lasers Surg Med. 2006;38(9):837-845. doi:10.1002/1sm.20385

28. Hsu CY, Jordan T, Dederich D, Wefel J. Effects of low-energy $\mathrm{CO}_{2}$ laser irradiation and the organic matrix on inhibition of enamel demineralization. J Dent Res. 2000;79(9):1725-1730. doi:10.1177/ 00220345000790091401

29. Pollick $\mathrm{H}$. The role of fluoride in the prevention of tooth decay. Pediatr Clin North Am. 2018;65(5):923-940. doi:10.1016/j.pcl.2018.05.014

30. Kim HN, Kim JB, Jeong SH. Remineralization effects when using different methods to apply fluoride varnish in vitro. $J$ Dent Sci. 2018;13(4):360-366. doi:10.1016/j.jds.2018.07.004

31. Vlacic J, Meyers I, Kim J, Walsh L. Laser-activated fluoride treatment of enamel against an artificial caries challenge: comparison of five wavelengths. Aust Dent J. 2007;52(2):101-105. doi:10.1111/ j.1834-7819.2007.tb00472.x

32. Rechmann P, Charland DA, Rechmann BM, Le CQ, Featherstone JD. In-vivo occlusal caries prevention by pulsed $\mathrm{CO}_{2}$ laser and fluoride varnish treatment-A clinical pilot study. Lasers Surg Med. 2013;45:302-310. doi:10.1002/1sm.22141

33. Zhao IS, Xue VW, Yin IX, Niu JY, Lo ECM, Chu CH. Use of a novel 9.3- $\mu \mathrm{m}$ carbon dioxide laser and silver diamine fluoride: prevention of enamel demineralisation and inhibition of cariogenic bacteria. Dent Mater. 2021;8:S0109-5641(21)00079-8.

34. Hsu DJ, Darling CL, Lachica MM, Fried D. Nondestructive assessment of the inhibition of enamel demineralization by $\mathrm{CO}_{2}$ laser treatment using polarization sensitive optical coherence tomography. J Biomed Opt. 2008;13(5):054027. doi:10.1117/ 1.2976113 
35. Can AM, Darling CL, Ho C, Fried D. Non-destructive assessment of inhibition of demineralization in dental enamel irradiated by a $\lambda=9.3-\mu \mathrm{m} \mathrm{CO}_{2}$ laser at ablative irradiation intensities with PS-OCT. Lasers Surg Med. 2008;40(5):342-349. doi:10.1002/1sm.20633

36. Lee R, Chan KH, Jew J, Simon JC, Fried D. Synergistic effect of fluoride and laser irradiation for the inhibition of the demineralization of dental enamel. Proceedings of SPIE - The International Society for Optical Engineering; 2017:10044.

37. Manesh SK, Darling CL, Fried D. Nondestructive assessment of dentin demineralization using polarization-sensitive optical coherence tomography after exposure to fluoride and laser irradiation. $J$ Biomed Mater Res Part B Appl Biomater. 2009;90B(2):802-812. doi:10.1002/jbm.b.31349

38. Rechmann P, Sherathiya K, Kinsel R, Vaderhobli R, Rechmann B. Influence of irradiation by a novel $\mathrm{CO}_{2} 9.3-\mu \mathrm{m}$ short-pulsed laser on sealant bond strength. Lasers Med Sci. 2017;32(3):609-620. doi:10.1007/s10103-017-2155-4

39. Rechmann P, Bartolome N, Kinsel R, Vaderhobli R, Rechmann BMT. Bond strength of etch-and-rinse and self-etch adhesive systems to enamel and dentin irradiated with a novel $\mathrm{CO}_{2} 9.3 \mu \mathrm{m}$ short-pulsed laser for dental restorative procedures. Lasers Med Sci. 2017;32 (9):1981-1993. doi:10.1007/s10103-017-2302-y
40. Nguyen D, Staninec M, Lee C, Fried D. High-speed scanning ablation of dental hard tissues with a lambda=9.3- $\mu \mathrm{m} \mathrm{CO}_{2}$ laser: heat accumulation and peripheral thermal damage. Lasers in Dentistry XVI: International Society for Optics and Photonics; 2010:754907.

41. Luk K, Zhao IS, Yu OY, Zhang J, Gutknecht N, Chu CH. Effects of 10,600 nm carbon dioxide laser on remineralizing caries: a literature review. Photobiomodul Photomed Laser Surg. 2020;38(2):59-65. doi:10.1089/photob.2019.4690

42. Kimura Y, Takahashi-Sakai K, Wilder-Smith P, Krasieva TB, Liaw LHL, Matsumoto K. Morphological study of the effects of $\mathrm{CO}_{2}$ laser emitted at $9.3 \mu \mathrm{m}$ on human dentin. J Clin Laser Med Surg. 2000;18(4):197-202. doi:10.1089/10445470050144047

43. Featherstone JD, Zhang S, Shariati M, McCormack SM. Carbon dioxide laser effects on caries-like lesions of dental enamel. Lasers Orthop Dent Vet Med. 1991;145-149.

\section{Publish your work in this journal}

Clinical, Cosmetic and Investigational Dentistry is an international, peer-reviewed, open access, online journal focusing on the latest clinical and experimental research in dentistry with specific emphasis on cosmetic interventions. Innovative developments in dental materials, techniques and devices that improve outcomes and patient satisfaction and preference will be highlighted. The manuscript management system is completely online and includes a very quick and fair peer-review system, which is all easy to use. Visit http://www.dovepress.com/testimonials.php to read real quotes from published authors. 